\title{
Monozygotic twins with trisomy 18: a report of discordant phenotype
}

Jerrold S Schlessel, W Ted Brown, Andrzej Lysikiewicz, Russell Schiff, Ann Leslie Zaslav

\begin{abstract}
The predicted incidence of liveborn monozygotic trisomy 18 twins is one per million births. The first case of liveborn monozygotic trisomy 18 twins was reported in 1989 and we report a second case in which striking phenotypic discordance existed. The probability of monozygotic trisomy 18 twinning and the mechanisms for phenotypic discordance in trisomic twins is discussed.
\end{abstract}

Trisomy 18 occurs at a rate of about 0.3 per 1000 newborn babies with a 3:1 preponderance of females to males. ${ }^{1}$ The monozygotic twin rate is 3.5 to 4 per 1000 births. ${ }^{2}$ The predicted incidence of these events occurring together is approximately one per million. However, the true incidence may be much lower as there has only been one reported observation ${ }^{3}$ of trisomy 18 in liveborn monozygotic twins. We report the second case of liveborn monozygotic twins with trisomy 18. Despite identical karyotypes, discordance for major congenital malformations was present.

Division of Perinatal Medicine, Department of Pediatrics, North Shore University Hospital-Cornell University Medical College, 300 Community Drive, Manhasset, New York 11030, USA.

J S Schlessel

Division of Human Genetics, Department of Pediatrics, North Shore University Hospital-Cornell University Medical College, Manhasset, New York 11030, USA. W T Brown, A L Zaslav

Division of Maternal-Fetal Medicine, Department of Obstetrics and Gynecology, North Shore University HospitaL-Cornell University Medical College, Manhasset, New York 11030, USA.

A Lysikiewicz

Division of Pediatric Cardiology, Department of Pediatrics, North Shore University Hospital-Cornell University Medical College, Manhasset, New York 11030, USA. $R$ Schiff

Correspondence to Dr Schlessel.

Received for publication 6 March 1990.

Accepted for publication 20 March 1990

\section{Case report}

A 26 year old white woman, gravida 2, para 1-0-0-1, with a twin pregnancy, was admitted to hospital at 27 weeks' gestation because of premature rupture of membranes and preterm labour. Ultrasonographic examination at this time showed discordant fetal measurements: biparietal diameters 71 and $60 \mathrm{~mm}$, and femur lengths 48 and $44 \mathrm{~mm}$ (values for twin A and twin $B$, respectively). Twin $A$, who had fetal measurements appropriate for gestational age, had a two vessel umbilical cord and an umbilical artery blood velocity systolic/diastolic ratio $(\mathrm{S} / \mathrm{D}$ ratio) $=$ 2.5-3.1. Twin B had a "lemon shaped appearance of the fetal head" (fig la) and a cystic spine defect at the level of the lumbar vertebrae consistent with a

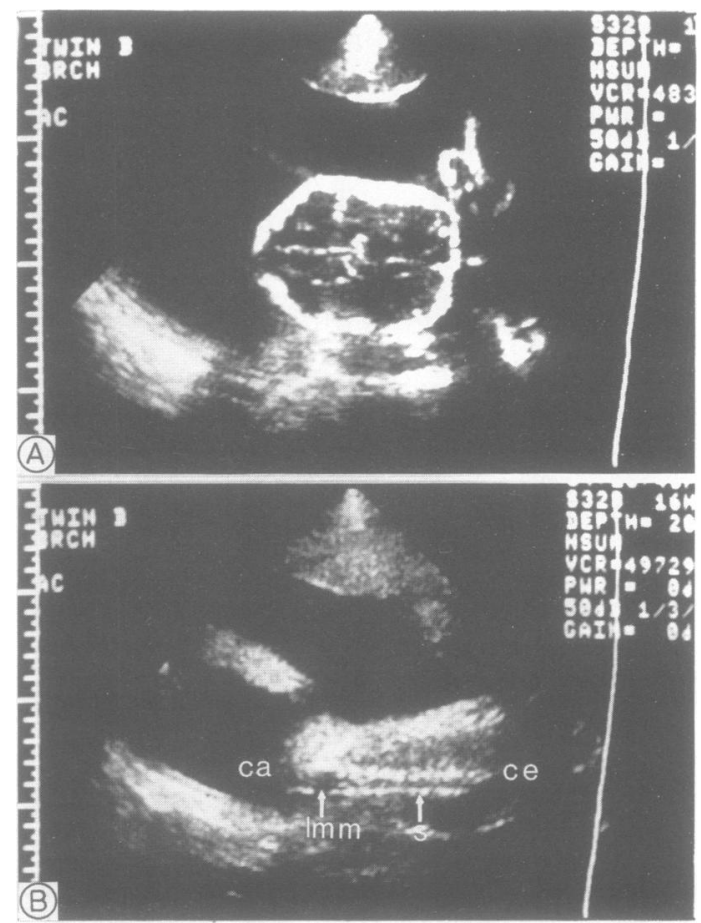

Figure 1 Ultrasonography of fetus twin $B$ showing $(A)$ lemon shaped fetal head, and $(B)$ fetal spine (s) with lumbar myelomeningocele ( $1 \mathrm{~mm}$ ): cephalad (ce) and caudad (ca) spine. 


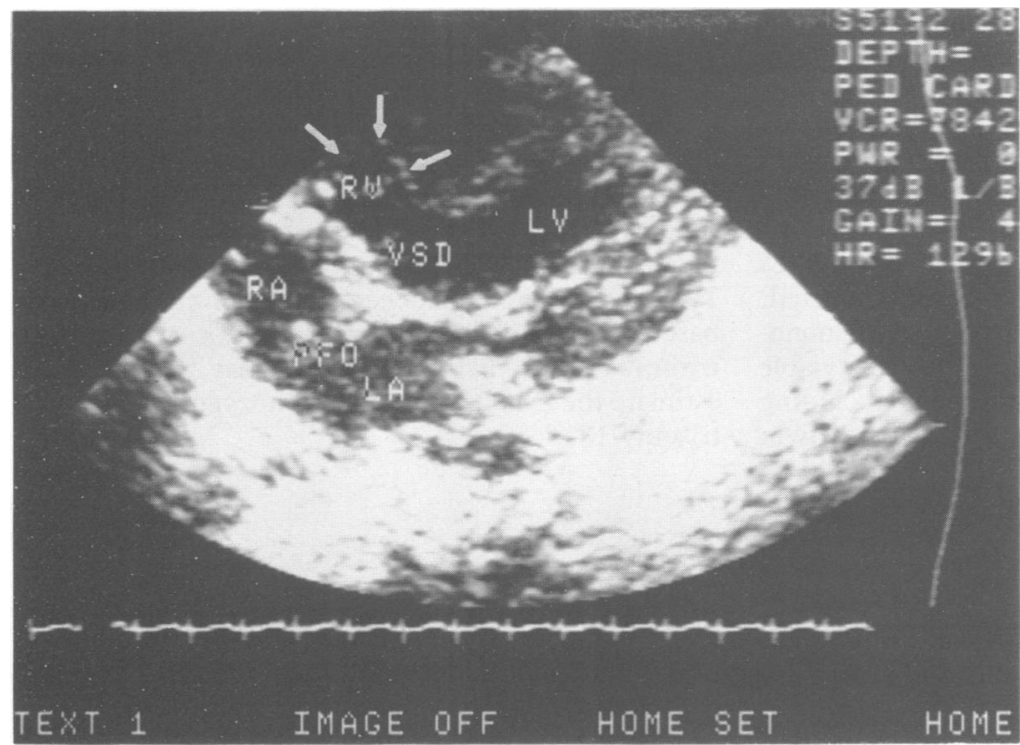

Figure 2 Echocardiogram of twin $A$ showing hypoplastic right ventricle $(R V)$. Arrows indicate $R V$ wall; posterior endocardial ventricular septal defect $(V S D) ;$ left ventricle $(L V)$; right atrium $(R A)$; left atrium (LA); and patent foramen ovale $(P F O)$.

myelomeningocele (fig lb). Polyhydramnios and a raised $S / D$ ratio $4=3 \cdot 5-4 \cdot 7$ were also noted.

The mother received betamethasone to induce fetal lung maturation and ritodrine for tocolysis to allow for 24 hours of steroid treatment. During the subsequent 24 hours, the patient broke through tocolysis and was delivered by caesarean section.

Twin A was a $923 \mathrm{~g}$ female who had no spontaneous respiratory effort. Resuscitation with positive pressure ventilation was instituted immediately after birth and Apgar scores were 7 and 9 at one and five minutes, respectively. Physical examination showed microphthalmia, grossly malformed right ear pinna with absent external auditory canal, right facial skin tag, micrognathia, overlapping of index over third finger, hypoplastic fingernails, a grade III/VI systolic ejection murmur with a single $S_{2}$, and rocker bottom feet. An echocardiogram showed a hypoplastic right ventricle and a posterior endocardial type ventricular septal defect (fig 2). A small tricuspid valve annulus with tricuspid regurgitation, absent right ventricular outflow tract, pulmonary atresia, and patent ductus arteriosus were also noted. An infusion of prostaglandin $E_{1}$ was started. A renal sonogram was within normal limits: right kidney length $=3.5 \mathrm{~cm}$ and left kidney $=3 \cdot 1 \mathrm{~cm}$. A bone marrow aspirate and blood sample were obtained four hours after birth for karyotype analysis using standard cytogenetic harvesting and banding techniques. ${ }^{56}$

Twin B was a $666 \mathrm{~g}$ female who also had no spontaneous respirations. Identical Apgar scores to those of twin A were assigned to twin B during positive pressure ventilation. Microphthalmia, a reducible omphalocele with herniation of intestine and overlying membrane, a $2 \times 2 \mathrm{~cm}$ open, leaking, lumbosacral myelomeningocele, overlapping of index over third finger, hypoplastic nails, and rocker bottom feet were noted. Neurosonogram showed a moderate degree of hydrocephalus. A blood sample for karyotyping was drawn.

The diagnosis of trisomy 18 was suspected in both twins in view of the physical findings. The karyotype of twin A was identified at 22 hours of life as trisomy 18 by bone marrow aspirate culture. The karyotypes of twins A and B were trisomy 18 on blood lymphocyte culture. Blood obtained from each twin confirmed monozygosity by identical DNA restriction fragment length polymorphisms for hypervariable loci $D 2 S 44$, D17S79, D14S13, and D18S27 (performed by Lifecodes Inc, Elmsford, NY). The infants were mechanically ventilated and received intravenous hydration, packed red blood cell transfusions, and ampicillin and gentamycin. Twin A died at 36 hours and twin B at 48 hours of life.

\section{Discussion}

These infants are the second reported cases of liveborn monozygotic trisomy 18 twins. Growth retardation and structural malformations were detected in one of the twins by fetal ultrasonography, raising the spectre of chromosomal abnormalities. Since the mother was in preterm labour, further prenatal diagnosis was not considered. These twins were discordant for their major congenital malformations, complex congenital heart disease in twin $\mathrm{A}$ and 
myelomeningocele, hydrocephalus, and omphalocele in twin B, even though concordance for genotype was established by DNA probes.

The first case of trisomy 18 in liveborn monozygotic twins differs from this case report in that less striking phenotypic discordance was reported: omphalocele in twin A and clitoromegaly in twin $\mathrm{B}^{3}$ Two cases of presumptive monozygotic trisomy 18 twins with only twin A liveborn have been reported. Neither study presented genetic evidence of monozygosity. In one report, ${ }^{7}$ one of the twins was viable and the other had major malformations including holoacardius. In the other report, the liveborn twin died at 15 minutes of age. ${ }^{8}$

In contrast to the apparent rarity of monozygotic trisomy 18 twinning, monozygotic twinning with trisomy 21 has been reported frequently and discussed extensively. $^{9-12}$ In 1968 , Zellweger ${ }^{13}$ reported 22 cases of monozygotic twins with Down's syndrome. Nevertheless, the frequency of liveborn monozygotic twins with trisomy 21 is less than the calculated expectation. ${ }^{14} 15$ It has been suggested that this decrease in the expected frequency of monozygotic twins with trisomy 21 results from increased embryonic or fetal wastage. ${ }^{16}$ Fetal wastage has been estimated as $65 \%$ in trisomy 21 versus $80 \%$ in trisomy 18. ${ }^{17}$ This may explain, in part, the very rare occurrence of liveborn monozygotic twins with trisomy 18, as observed here and reported by Shah $e t$ $a l .^{3}$ Although the calculated probability of liveborn monozygotic twins with trisomy 18 is approximately one in one million, the rarity of observations suggest that there may be a further increase in fetal wastage in trisomy 18 in the setting of twins.

The twins in this report were observed to be discordant for phenotypic features as seen in differing major congenital malformations. Two explanations exist for congenital malformation in twins: (1) the germ cell theory, which assumes the defect to be present in the gametes, and (2) the environmental theory, which assumes the defects occur after fertilisation. ${ }^{18}$ Since the twins in this report were monozygotic and, therefore, of similar genetic constitution, it seems most likely that intrauterine environmental effects caused the differences in their malformations. Loevy et $a l^{19}$ noted discordant anomalies in mono- zygotic twins with trisomy 13 and suggested that the presence of a chromosomal abnormality itself may predispose to a variable range of phenotypic anomalies.

This case of liveborn monozygotic twins with trisomy 18 is the second reported observation. We suggest that the increased fetal wastage seen in trisomy 18 acts to reduce the overall observed incidence of liveborn monozygotic twins with trisomy 18. The predicted incidence of one per million births, based on the probability of monozygotic twinning and trisomy 18 occurring together, may greatly overestimate the true incidence of monozygotic twins with trisomy 18.

1 Smith DW. Trisomy 18 syndrome. In: Recognizable patterns of human malformation. 4th ed. Philadelphia: Saunders, 1988: 16-19.

2 Bulmer MG. The familial incidence of twinning. Ann Hum Genet 1960;24:1-3.

3 Shah DM, Jeanty P, Dev VG, et al. Diagnosis of trisomy 18 in monozygotic twins by cordocentesis. Am $\mathcal{F}$ Obstet Gynecol 1989;160:214-5.

4 Schulman H, Fleischer A, Stern W, et al. Umbilical velocity wave ratios in human pregnancy. Am $\mathcal{F}$ Obstet Gynecol 1984;148: 985-9.

5 Yunis JJ. New chromosome techniques in the study of human neoplasia. Hum Pathol 1981;12:540-9.

6 Seabright M. A rapid banding technique for human chromosomes. Lancet 1971;ii:971-3.

7 Bhatnagar KP, Sharma SC, Bisker J. The holoacardius: a correlative computerized tomographic, radiologic, and ultrasonographic investigation of a new case with review of literature. Acta Genet Med Gemellol (Roma) 1986;35:77-89.

8 Lapi E, Benedetti A, Biondi A. Sindrome di Edwards in un coppia gemellare. Minerva Ginecol 1981;33:1151-4.

9 Lipovetskaia NG. A case of Down's disease in both uniovular twins. Pediatriia 1964;43:102-3.

10 Rasore-Quartino A. Gemelli MZ con mongolismo concordante. Acta Genet Med Gemellol (Roma) 1967;16:395-401.

11 Shiono H, Kasahara S, Toyoguchi A, et al. Genetic studies on twins of Down's syndrome with 47-chromosomes. Tohoku $\mathcal{J}$ Exp Med 1971;105:309-16.

12 Young RJ. Mongolism in both of monozygotic twins. Arch Dis Child 1954;29:55-9.

13 Zellweger $\mathrm{H}$. Familial aggregates of the 21-trisomy syndrome. Ann NY Acad Sci 1968;155:784-92.

14 Smith A. A note on mongolism in twins. Br $\mathrm{f}$ Prev Soc Med 1955;9:212-3

15 Allen G, Baroff GS. Mongoloid twins and their siblings. Acto Genet 1955;5:294-326.

16 Keay AJ. The significance of twins in mongolism in the light of new evidence. F Ment Defic Res 1958;2:1-7.

17 Kelly TE. Clinical genetics and genetic counselling. Chicago: Yearbook Medical Publishers, 1986:82.

18 Schinzel A, Smith DW, Miller JR. Monozygotic twinning and structural defects. F Pediatr 1979;95:921-30.

19 Loevy HT, Miller M, Rosenthal IM. Discordant twins with trisomy 13. Acta Genet Med Gemellol (Roma) 1985;34:185-8. 